\title{
Impedance Modelling and Stability Analysis of Diode- Rectifier based HVDC Connected Offshore Wind Farms
}

\author{
Lujie Yu, Lie Xu, Senior Member, Jiebei Zhu, Senior Member, Rui Li
}

\begin{abstract}
This paper investigates the stability of diode rectifier based HVDC (DR-HVDC) connected offshore wind farms. The impedance model of the DR-HVDC connected offshore wind farms in dq frame is analytically developed and is validated by comparing its impedances to those obtained from frequency scanning of time domain EMT model in PSCAD/EMTDC. Based on the impedance model, the impacts of the sizes of DR-HVDC DC smoothing reactors and $A C$ filters on offshore system stability are analyzed. It shows reduced DC smoothing reactance degrades the d-axis stability margin and can potentially lead to system instability. Higher bandwidth of offshore AC voltage control of wind turbine line side converter is proposed to minimize such instability potential. The analysis also shows that reduced AC filters size helps to increase $q$-axis stability margin and leads to a more stable system. Moreover, stability analysis considering the interaction between WTs is conducted and it reveals that the WT $P-V$ control has a significant impact on the stability of the DRHVDC connected WTs.
\end{abstract}

Index Terms-diode rectifier based HVDC, grid forming wind turbine control, impedance modelling, interaction between offshore wind farms and HVDC, stability analysis.

\section{INTRODUCTION}

$\mathrm{M}$ any large offshore wind farms are being developed and more have been planned. The rapid development of offshore wind power generation requires efficient power transmission technology [1]. Comparing with high voltage alternating current (HVAC), high voltage direct current (HVDC) offers significant advantages for integrating large offshore wind farms over long distance, such as lower losses and cost [2].

However, offshore wind farms connected with HVDC lead to a converter-dominated network, with no rotating mass which physically links the generated power with the frequency and no resistive loads which provide sufficient damping [3, 4]. In such isolated offshore network, the interaction between wind turbine (WT) converters and HVDC offshore converter may pose challenges to its stable operation. For instance, oscillation was reported when voltage source converter based HVDC (VSCHVDC) is used to transmit the offshore wind power in North Sea, resulting in the shut-down of wind farms for several months [5]. The small signal impedance-based analysis is now regarded as an effective way to clarify the interaction between WTs and HVDC systems $[6,7]$. When the detailed parameters of wind turbines are difficult to obtain and only a black box WT model is provided by the manufactory, the impedance-based analysis can be readily used to determine the system stability

This work was supported in part by the National Natural Science Foundation of China under Grant 51977143.

Lujie Yu and Jiebei Zhu are with the School of Electrical and information Engineering, Tianjin University, Tianjin, China.

Lie $\mathrm{Xu}$ and Rui Li are with the Department of Electronic and Electrical Engineering, University of Strathclyde, Glasgow, G1 1XW UK. after obtaining the output impedance of the wind farms. With this approach, the feasibility/effectiveness of stability analysis for such a system can be significantly improved. In [6], the dq impedances of the WT and two level VSC-HVDC are derived and the bandwidth ratio of the subsystem is suggested to improve system stability. In [7], the modular multilevel converter (MMC) impedance is presented and the impact of circulating current control on the offshore system stability is investigated.

Recently, diode rectifier based HVDC (DR-HVDC), where an uncontrolled diode rectifier is used at the offshore station and an MMC is used at the onshore station, has received increased attentions, especially for large and remote offshore wind farm connection [8-10]. When replacing the offshore VSC with the diode rectifier, it provides the advantages of lower investment, lower space requirement, higher efficiency and improved robustness. It has the potential to reduce the transmission loss by $30 \%$, offshore substation topside volume by $80 \%$ and total cost by $30 \%$ [11]. However, the use of DR poses challenges for the start-up of the offshore wind farms due to its unidirectional characteristic. To overcome this issue, $[11,12]$ propose a scheme where umbilical AC cables operate in parallel with the DR-HVDC link. In [13, 14], additional battery storage is installed in the WTs to power the auxiliaries during the initial energization. In addition, this transmission technology requires the WTs to take more control responsibilities, e.g. the WT line side converters (LSCs) need to provide grid-forming capability rather than work on grid-following mode. References $[8,9]$ propose a WT grid forming control, where the current used to establish the offshore voltage and frequency of point of common coupling (PCC) is shared among all the WT LSCs. However, the need for measuring the voltage and current at PCC requires high-speed communications among the WTs. Reference [15] propose a fixed frequency control based on global positioning system (GPS) to provide a common angular reference for all the WTs. Such control solution avoids the need for remote measurements but can potentially increase the control system cost and reduce system reliability. A decentralized WT control is proposed in [16, 17], where a reactive power frequency droop control is adopted to regulate the WT phase angle, but such control without the use of PLL may pose challenges during initial start-up, as each WT has to synchronize with the offshore network before de-blocking. In $[14,18,19]$, a distributed PLL based WT control is proposed, which enables each WT to form the offshore network based on local variables and behave as distributed $\mathrm{AC}$ voltage sources with synchronization capability.

However, the stability analysis of DR-HVDC connected offshore wind farms has not been thoroughly conducted. As the 
offshore network in such systems is made up of uncontrolled diode rectifier and grid forming WT LSCs, the interaction between them is very different from the interaction between MMC-HVDC and grid following WT LSCs. Therefore, the findings obtained from the research on MMC-HVDC system cannot be applied to the DR-HVDC connected offshore wind farm system. Thus, this paper carries out the impedance modelling and stability analysis of DR-HVDC connected offshore wind farms. The main contributions of this paper are summarized as:

- A small signal impedance model of DR-HVDC is analytically developed. Comparing with the small signal model presented in [19], the model developed in this paper reflects the frequency dependent overlap angle dynamics. Impedance comparison between the developed model and time domain model shows the modelling accuracy is significantly improved.

- As the sizes of the DR-HVDC DC smoothing reactor and AC filters play a decisive role in determining the weight, volume, and cost of the offshore station, the impacts of reduced DC smoothing reactors and $\mathrm{AC}$ filters on the offshore system stability are analyzed using the impedance models.

- Stability analysis considering the interaction between WTs is conducted and it reveals that the WT $P-V$ control has a significant impact on the stability of the DR-HVDC connected WTs.

The rest of this paper is organized as follows. Section II presents the structure of DR-HVDC connected offshore wind farms. The impedances of DR-HVDC and the offshore wind farms are developed in Section III and IV, respectively. Section $\mathrm{V}$ presents the stability analysis based on the developed impedance model, considering the variations of DC smoothing reactors and AC filters, and Section VI draws conclusions.

\section{STRUCTURE OF DR-HVDC CONNECTED OFFSHORE WIND FARMS}

Fig. 1 presents the diagram of 1000 MW DR-HVDC connected offshore wind farms, which consist of 10 strings. Each string is made up of 10 permanent magnet synchronous generators (PMSG) based WTs. Each WT is rated at $10 \mathrm{MW}$ and connected to the collection system through a step-up transformer from $690 \mathrm{~V}$ to $66 \mathrm{kV}$. The offshore HVDC station includes a 12-pulse diode rectifier with star-star and star-delta connected transformers, AC filters and DC smoothing reactors. The onshore HVDC station uses modular multilevel converter (MMC), which controls the DC voltage of the HVDC system. As this paper focuses on the analysis of interaction between offshore WT LSCs and DR-HVDC, the WT generation side converters are simplified as DC sources $[8,9]$. References [20, 21] demonstrate that the back-to-back converters in PMSG-WT decouples the generator side and line side and the states of the generator side do not actively participate in the offshore network oscillatory modes. Meanwhile, the WTs are represented as an aggregated LSC and the onshore MMC is simplified as a DC source.

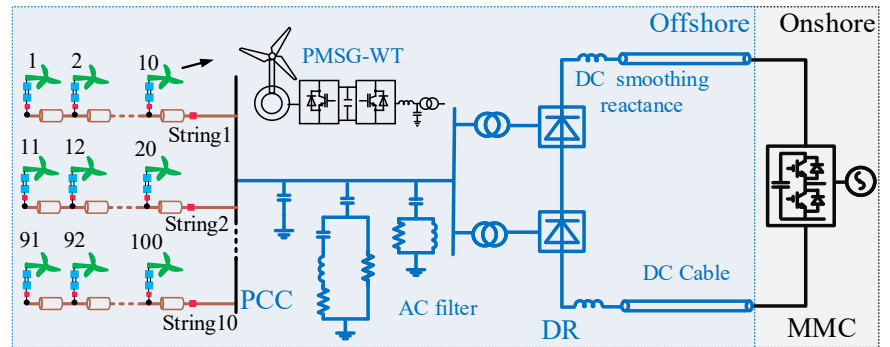

Fig. 1 DR-HVDC connected offshore wind farms.

\section{IMPEDANCE MODELLING OF DR-HVDC}

\section{A. DR-HVDC impedance modelling}

For the diode rectifier, it can be considered as a current source on the AC side and a voltage source on the DC side [22]. Thus, with AC voltage and DC current disturbances $\left(\Delta v_{d}, \Delta v_{q}\right.$ and $\left.\Delta I_{d c}\right)$, the small signal DC voltage $\left(\Delta V_{d c}\right)$, and AC current of the diode rectifier $\left(\Delta i_{d}\right.$ and $\left.\Delta i_{q}\right)$ in dq domain can be represented in a generic form as

$$
\left\lfloor\begin{array}{c}
\Delta i_{d} \\
\Delta i_{q} \\
\Delta V_{d c}
\end{array}\right\rfloor=\left[\begin{array}{lll}
K_{11} & K_{12} & K_{13} \\
K_{21} & K_{22} & K_{23} \\
K_{31} & K_{32} & K_{33}
\end{array}\right]\left\lfloor\begin{array}{c}
\Delta v_{d} \\
\Delta v_{q} \\
\Delta I_{d c}
\end{array}\right\rfloor
$$

The DC side dynamics can be considered using the equivalent DC impedance as

$$
\Delta V_{d c}=\Delta U_{d c} Z_{d c}
$$

Thus, the diode rectifier AC dynamics in $\mathrm{dq}$ domain are described as $\left[\begin{array}{l}\Delta v_{d} \\ \Delta v_{q}\end{array}\right]=\mathbf{Z}_{\mathbf{D R}}\left[\begin{array}{l}\Delta i_{d} \\ \Delta i_{q}\end{array}\right]$, where the equivalent $\mathrm{AC}$ impedance is given as

$$
\mathbf{Z}_{\mathbf{D R}}=\mathbf{Y}_{\mathbf{D R}}^{\mathbf{- 1}}=\left[\begin{array}{ll}
Y_{D R d d} & Y_{D R d q} \\
Y_{D R q d} & Y_{D R q q}
\end{array}\right]^{-1}
$$

and

$$
\begin{array}{ll}
Y_{D R d d}=K_{11}+\frac{K_{13} K_{31}}{Z_{d c}-K_{33}} & Y_{D R d q}=K_{12}+\frac{K_{13} K_{32}}{Z_{d c}-K_{33}} \\
Y_{D R q d}=K_{21}+\frac{K_{23} K_{31}}{Z_{d c}-K_{33}} & Y_{D R q q}=K_{22}+\frac{K_{23} K_{32}}{Z_{d c}-K_{33}}
\end{array}
$$

The following subsections present how the elements of $K_{m n}$ in (1) are derived.

\section{1) Diode rectifier DC voltage dynamics}

As the DC voltage of a 6-pulse diode rectifier consists of six repeated segments in each fundamental cycle, it is sufficient to only consider one segment (i.e. $\pi / 3$ interval). Here, the segment when the conduction mode $\mathrm{D}_{6} \mathrm{D}_{5}\left(\mathrm{D}_{6}\right.$ and $\mathrm{D}_{5}$ conducting) is commuted to $\mathrm{D}_{6} \mathrm{D}_{1}\left(\mathrm{D}_{6}\right.$ and $\mathrm{D}_{1}$ conducting) is studied, as shown in Fig. 2 . The DC voltage $\left(V_{d c p}\right.$ and $\left.V_{d c n}\right)$ and $\mathrm{AC}$ current $\left(i_{a}\right)$ during and after the commutation in this segment are presented in Fig. 3.

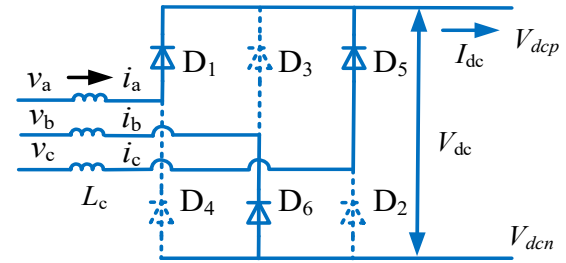

Fig. 2 Diode rectifier commutation from conduction mode $D_{6} D_{5}$ to $D_{6} D_{1}$. 


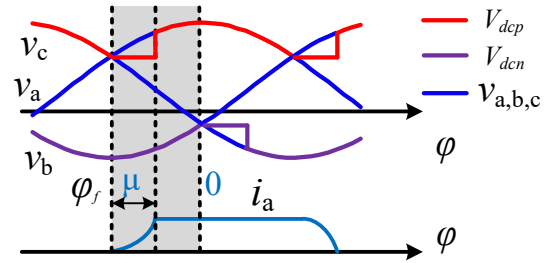

Fig. 3 DC voltage and current during and after the commutation.

During the commutation from $\mathrm{D}_{6} \mathrm{D}_{5}$ to $\mathrm{D}_{6} \mathrm{D}_{1}$, the three-phase $\mathrm{AC}$ current dynamics are expressed as

$$
L_{c} \frac{d i_{a}}{d t}=v_{a}-V_{d c p}, \quad L_{c} \frac{d i_{b}}{d t}=v_{b}+V_{d c n}, \quad L_{c} \frac{d i_{c}}{d t}=v_{c}-V_{d c p}
$$

where

$$
i_{a}+i_{c}=-i_{b}=I_{d c}
$$

Thus, the DC voltages of the diode rectifier during and after the commutation are given respectively as

$$
\begin{gathered}
V_{d c}^{c}=\frac{v_{a}+v_{c}}{2}-v_{b}-\frac{3}{2} L_{c} \frac{d I_{d c}}{d t} \\
V_{d c}^{n c}=v_{a}-v_{b}-2 L_{c} \frac{d I_{d c}}{d t}
\end{gathered}
$$

Representing the $\mathrm{AC}$ voltage in dq domain, the DC voltages during and after commutation are expressed as

$$
\begin{aligned}
& V_{d c}^{c}=\frac{3}{2}\left[v_{d} \cos \left(\varphi+\frac{\pi}{3}\right)-v_{q} \sin \left(\varphi+\frac{\pi}{3}\right)\right]-\frac{3}{2} L_{c} \frac{d I_{d c}}{d t} \\
& \text { when }-\frac{\pi}{3}<\varphi<-\frac{\pi}{3}+\mu \\
& V_{d c}^{n c}=\sqrt{3}\left[v_{d} \cos \left(\varphi+\frac{\pi}{6}\right)-v_{q} \sin \left(\varphi+\frac{\pi}{6}\right)\right]-2 L_{c} \frac{d I_{d c}}{d t} \\
& \text { when }-\frac{\pi}{3}+\mu<\varphi<0
\end{aligned}
$$

The average $\mathrm{DC}$ voltage over one segment is

$$
\begin{aligned}
V_{d c} & =\frac{3}{\pi}\left\lfloor\int_{-\frac{\pi}{3}}^{-\frac{\pi}{3}+\mu} V_{d c}^{c} d \varphi+\int_{-\frac{\pi}{3}+\mu}^{0} V_{d c}^{n c} d \varphi \mid\right. \\
& =\frac{3 \sqrt{3}}{2 \pi}\left[v_{d}(1+\cos \mu)-v_{q} \sin \mu\right]-s\left(2-\frac{3 \mu}{2 \pi}\right) L_{c} I_{d c}
\end{aligned}
$$

Linearizing (11) yields the DC voltage deviation as

$$
\begin{aligned}
\Delta V_{d c} & =\frac{3 \sqrt{3}}{2 \pi}\left[\Delta v_{d}\left(1+\cos \mu_{0}\right)-v_{d 0} \sin \mu_{0} \Delta \mu\right. \\
& \left.-\Delta v_{q} \sin \mu_{0}-v_{q 0} \cos \mu_{0} \Delta \mu\right]-s\left(2-\frac{3 \mu}{2 \pi}\right) L_{c} \Delta I_{d c}
\end{aligned}
$$

Thus,

$$
\begin{aligned}
& K_{31}=\frac{\Delta V_{d c}}{\Delta v_{d}}=\frac{3 \sqrt{3}}{2 \pi}\left[1+\cos \mu_{0}\right]+\frac{3 \sqrt{3}}{2 \pi}\left(-v_{d 0} \sin \mu_{0}-v_{q 0} \cos \mu_{0}\right) \frac{\Delta \mu}{\Delta v_{d}} \\
& K_{32}=\frac{\Delta V_{d c}}{\Delta v_{q}}=-\frac{3 \sqrt{3}}{2 \pi} \sin \mu_{0}+\frac{3 \sqrt{3}}{2 \pi}\left(-v_{d 0} \sin \mu_{0}-v_{q 0} \cos \mu_{0}\right) \frac{\Delta \mu}{\Delta v_{q}} \\
& K_{33}=\frac{\Delta V_{d c}}{\Delta I_{d c}}=-s\left(2-\frac{3 \mu}{2 \pi}\right) L_{c}+\frac{3 \sqrt{3}}{2 \pi}\left(-v_{d 0} \sin \mu_{0}-v_{q 0} \cos \mu_{0}\right) \frac{\Delta \mu}{\Delta I_{d c}}
\end{aligned}
$$

\section{B. Commutation overlap angle dynamics}

As can be seen in (13)-(15), the small signal DC voltage variation depends on the dynamics of the commutation overlap angle. This subsection describes how the input disturbance affects the commutation overlap angle.

According to (5) and (6), the phase 'a' current $i_{\mathrm{a}}$ is

$$
2 L_{c} \frac{d i_{a}}{d t}-L_{c} \frac{d i_{d c}}{d t}=v_{a}-v_{c}
$$

Considering the impact of phase ' $a$ ' current by the DC current and $\mathrm{AC}$ voltages separately, $i_{\mathrm{a}}$ is represented as two parts

$$
i_{a}=i_{1 a}+i_{2 a}
$$

where $i_{1 \mathrm{a}}$ and $i_{2 \mathrm{a}}$ represent the parts of the current determined by the DC current $I_{\mathrm{dc}}$ and the AC voltage, respectively, as

$$
\begin{aligned}
& 2 L_{c} \frac{d i_{1 a}}{d t}=L_{c} \frac{d I_{d c}}{d t} \\
& 2 L_{c} \frac{d i_{2 a}}{d t}=v_{a}-v_{c}
\end{aligned}
$$

According to (17), $i_{\mathrm{a}}$ at the end of commutation, i.e. when $\varphi=$ $\varphi_{\mathrm{f}}+\mu$, is given as

$$
i_{a}\left(\varphi_{f}+\mu\right)=i_{1 a}\left(\varphi_{f}+\mu\right)+i_{2 a}\left(\varphi_{f}+\mu\right)
$$

where

$$
\begin{gathered}
i_{a}\left(\varphi_{f}+\mu\right)=I_{d c}\left(\varphi_{f}+\mu\right) \\
i_{1 a}\left(\varphi_{f}+\mu\right)=\frac{1}{2}\left[I_{d c}\left(\varphi_{f}+\mu\right)-I_{d c}\left(\varphi_{f}\right)\right] \\
i_{2 a}\left(\varphi_{f}+\mu\right)=i_{2 d}\left(\varphi_{f}+\mu\right) \cos \left(\varphi_{f}+\mu\right)-i_{2 q}\left(\varphi_{f}+\mu\right) \sin \left(\varphi_{f}+\mu\right) \\
-\left[i_{2 d}\left(\varphi_{f}\right) \cos \left(\varphi_{f}\right)-i_{2 q}\left(\varphi_{f}\right) \sin \left(\varphi_{f}\right)\right]
\end{gathered}
$$

Linearizing (20) yields

$$
\begin{aligned}
& \frac{1}{2}\left[\Delta I_{d c}\left(\varphi_{f}+\mu\right)+\Delta I_{d c}\left(\varphi_{f}\right)\right]= \\
& \Delta i_{2 d}\left(\varphi_{f}+\mu\right) \cos \left(\varphi_{f}+\mu\right)-\Delta i_{2 q}\left(\varphi_{f}+\mu\right) \sin \left(\varphi_{f}+\mu\right) \\
& -i_{2 d}\left(\varphi_{f}+\mu\right) \sin \left(\varphi_{f}+\mu\right) \Delta \mu-i_{2 q}\left(\varphi_{f}+\mu\right) \cos \left(\varphi_{f}+\mu\right) \Delta \mu \\
& -\left[\Delta i_{2 d}\left(\varphi_{f}\right) \cos \left(\varphi_{f}\right)-\Delta i_{2 q}\left(\varphi_{f}\right) \sin \left(\varphi_{f}\right)\right]
\end{aligned}
$$

Transforming (24) to Laplace domain, and also transforming the variables with angle at $\varphi_{f}+u$ to the variables at $\varphi_{f}$ [23], as

$$
L\left[\Delta i_{2 d q}\left(\varphi_{f}\right)\right]=e^{-s u / \omega_{0}} L\left[\Delta i_{2 d q}\left(\varphi_{f}+u\right)\right]
$$

equation (24) can be represented as

$$
\begin{aligned}
& -\frac{1}{2} \Delta I_{d c}\left(1+e^{-s \mu_{0} / \omega_{0}}\right)+\Delta i_{2 d}\left[\cos \left(u_{0}-\frac{\pi}{3}\right)-\frac{1}{2} e^{-s \mu_{0} / \omega_{0}}\right] \\
& -\Delta i_{2 q}\left[\sin \left(u_{0}-\frac{\pi}{3}\right)+\frac{\sqrt{3}}{2} e^{-s \mu_{0} / \omega_{0}}\right] \\
& -\Delta \mu\left[i_{2 d 0} \sin \left(u_{0}-\frac{\pi}{3}\right)+i_{2 q 0} \cos \left(u_{0}-\frac{\pi}{3}\right)\right]=0
\end{aligned}
$$

As $i_{2 \mathrm{a}}$ is determined by the AC voltage shown in (19), $i_{2 \mathrm{dq}}$ can be described as

$$
\left[\begin{array}{l}
\Delta i_{2 d} \\
\Delta i_{2 q}
\end{array}\right]=\left[\begin{array}{ll}
G_{11}(s) & G_{12}(s) \\
G_{21}(s) & G_{22}(s)
\end{array}\right]\left[\begin{array}{l}
\Delta v_{d} \\
\Delta v_{q}
\end{array}\right]
$$

where

$$
\left[\begin{array}{ll}
G_{11} & G_{12} \\
G_{21} & G_{22}
\end{array}\right]=\frac{1}{4 L_{c}\left(s^{2}+\omega_{0}^{2}\right)}\left[\begin{array}{cc}
3 s-\sqrt{3} \omega_{0} & \sqrt{3} s+3 \omega_{0} \\
-\sqrt{3} s-3 \omega_{0} & 3 s-\sqrt{3} \omega_{0}
\end{array}\right]
$$

Combining (26) and (27), the commutation overlap deviations $\frac{\Delta \mu}{\Delta v_{d}}, \frac{\Delta \mu}{\Delta v_{q}}$ and $\frac{\Delta \mu}{\Delta I_{d c}}$ are obtained. The details are given in Appendix A. 


\section{Diode rectifier AC current dynamics}

For the diode rectifier AC side current, during the commutation interval, it is described as

$$
i_{a}=i_{a}, \quad i_{b}=-I_{d c}, \quad i_{c}=I_{d c}-i_{a}
$$

Through Park transformation, the d-axis AC current during the commutation $i_{d i}^{c}$ is expressed as

$$
i_{d i}^{c}=\frac{2 \sqrt{3}}{3}\left[i_{a} \sin \left(\varphi+\frac{\pi}{3}\right)-I_{d c} \sin \varphi\right]
$$

where

$$
\begin{aligned}
& i_{a}=i_{2 d}(\varphi) \cos \varphi-i_{2 q}(\varphi) \sin \varphi+\frac{1}{2} I_{d c}(\varphi) \\
& -i_{2 d}\left(\varphi_{f}\right) \cos \left(\varphi_{f}\right)+i_{2 q}\left(\varphi_{f}\right) \sin \left(\varphi_{f}\right)-\frac{1}{2} I_{d c}\left(\varphi_{f}\right)
\end{aligned}
$$

The average d-axis current $i_{d}^{c}$ during the commutation is

$$
\begin{aligned}
i_{d}^{c}= & \frac{3}{\pi} \int_{-\frac{\pi}{3}}^{-\frac{\pi}{3}+\mu} i_{d i}^{c} d \varphi=\frac{2 \sqrt{3}}{\pi}\left[\frac{-\frac{1}{2} \cos 2 \mu-\frac{\sqrt{3}}{2} \sin 2 \mu+\frac{1}{2}+\sqrt{3} \mu}{4} i_{2 d}\right. \\
& -\frac{-\frac{1}{2} \sin 2 \mu+\frac{\sqrt{3}}{2} \cos 2 \mu-\frac{\sqrt{3}}{2}+\mu}{4} i_{2 q}+\frac{1}{2} I_{d c}(1-\cos \mu) \\
& \left.-\frac{1}{2} \frac{\omega_{0} m}{s^{2}+\omega_{0}^{2}} i_{2 d}-\frac{\sqrt{3}}{2} \frac{\omega_{0} m}{s^{2}+\omega_{0}^{2}} i_{2 q}-\frac{1}{2} \frac{\omega_{0} m}{s^{2}+\omega_{0}^{2}} I_{d c}\right]
\end{aligned}
$$

where

$$
m=\omega_{0}-\left(\omega_{0} \cos \mu_{0}+s \sin \mu_{0}\right) e^{-s \mu_{0} / \omega_{0}}
$$

On the other hand, during the non-commutation period, the $\mathrm{AC}$ current of the diode rectifier is

$$
i_{a}=I_{d c}, i_{b}=-I_{d c}, i_{c}=0
$$

Thus, the d-axis AC current $i_{d i}^{n c}$ and its average $i_{d}^{n c}$ during non-commutation period are expressed as

$$
\begin{gathered}
i_{d i}^{n c}=-\frac{2 \sqrt{3}}{3} I_{d c} \sin \left(\varphi-\frac{\pi}{3}\right) \\
i_{d}^{n c}=\frac{3}{\pi} \int_{-\frac{\pi}{3}+\mu}^{0} i_{d i}^{n c} d \varphi=\frac{2 \sqrt{3}}{\pi} I_{d c}\left[\frac{1}{2}+\cos \left(\mu+\frac{\pi}{3}\right)\right]
\end{gathered}
$$

After linearization of (32) and (36), $K_{11}, K_{12}$ and $K_{13}$ can be obtained as detailed in Appendix B. Similarly, $K_{21}, K_{22}$ and $K_{23}$ can be obtained as presented in Appendix B.

\section{DR-HVDC impedance modelling validation}

To validate the derived DR-HVDC impedance model, frequency scanning is conducted in PSCAD/EMTDC, where a specific frequency signal is injected into the DR-HVDC time domain model and the output signal with the same frequency is recorded for impedance/admittance calculation [18]. The model parameters are shown in Appendix C. The diode rectifier AC filters are also included during the frequency scanning, their dynamics can be found in [19] and the admittance of total filter is the sum of the admittances of DR reactive power compensation, low pass filter and high pass filter. Fig. 4 presents the magnitudes and phases of the DR-HVDC admittances from the model developed in this paper, admittances from the small signal model in [19], and admittances from time domain model. The red solid lines are the results from the developed analytical model in this paper, the black dash lines are the results from the model in [19] and the blue dots represent the frequency scanning results from the time domain model. As can be seen, the frequency responses from the model developed in this paper are in excellent agreements with those from time domain frequency scanning, while the frequency responses from the model presented in [19] show some errors, especially the $Y_{d q}$ and $Y_{q q}$ responses.
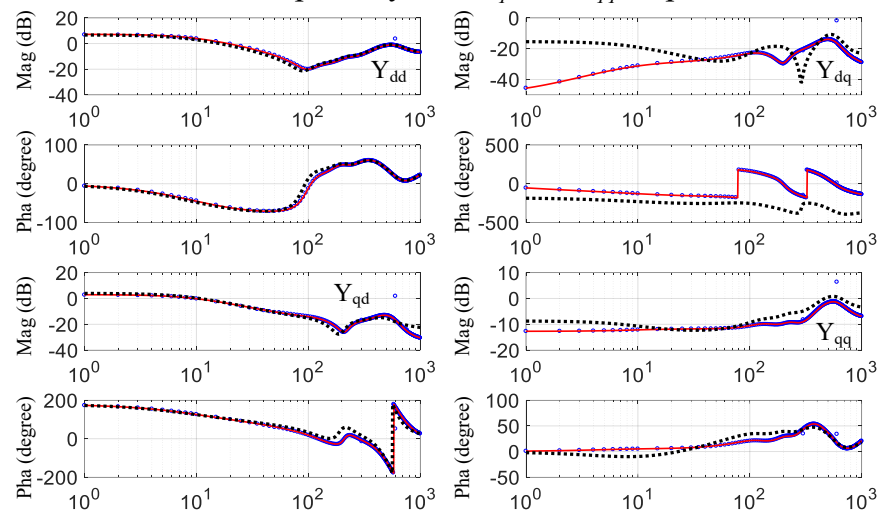

Fig. 4 Admittances of derived model (red solid), admittances of model in [19] (black dash) and frequency scanning results (blue dot).

\section{IMPEDANCE MODELLING OF WT LSC}

A. WT LSC impedance modelling with inner current and outer voltage control

Fig. 5 (a) presents the WT LSC with both the inner current control and outer voltage control [14], and the corresponding small-signal impedance model is shown in Fig. 5 (b). Thus, its impedance is expressed as

$$
\begin{aligned}
& \mathbf{Z}_{\mathrm{vi}}=\mathbf{v}_{\mathrm{f}} / \mathbf{i}_{\mathrm{s}}=-\mathbf{Z}_{\mathbf{C}}\left(\mathbf{I}-\mathbf{Y}_{\mathbf{L}} \mathbf{G}_{\mathrm{del}} \mathbf{G}_{\mathrm{dei}}\right) \\
& \left.\qquad \begin{array}{l}
\mathbf{I}-\mathbf{Y}_{\mathbf{L}} \mathbf{G}_{\mathrm{del}} \mathbf{G}_{\mathrm{dei}}+\mathbf{Z}_{\mathbf{C}} \mathbf{Y}_{\mathbf{L}}+\mathbf{Y}_{\mathbf{L}} \mathbf{G}_{\mathrm{del}} \mathbf{G}_{\mathrm{ci}} \\
-\mathbf{Z}_{\mathbf{C}} \mathbf{Y}_{\mathbf{L}} \mathbf{G}_{\mathrm{del}} \mathbf{G}_{\mathrm{ci}} \mathbf{G}_{\mathrm{dev}}+\mathbf{Z}_{\mathbf{C}} \mathbf{Y}_{\mathbf{L}} \mathbf{G}_{\mathrm{del}} \mathbf{G}_{\mathrm{ci}} \mathbf{G}_{\mathrm{cv}}-\mathbf{Z}_{\mathbf{C}} \mathbf{Y}_{\mathbf{L}} \mathbf{G}_{\mathrm{del}}
\end{array}\right)^{-1}
\end{aligned}
$$

where the WT inductance admittance $\mathbf{Y}_{\mathbf{L}}$, WT capacitance impedance $\mathbf{Z}_{\mathbf{C}}$, current control matrix $\mathbf{G}_{\mathbf{c i}}$, current control decoupling $\mathbf{G}_{\text {dei }}$ term, time delay term $\mathbf{G}_{\text {del }}$ caused by the PWM delay ( $\left.T_{\text {delay }}\right)$, voltage control matrix $\mathbf{G}_{\mathbf{v i}}$ and voltage control decoupling $\mathbf{G}_{\mathbf{d e v}}$ term are expressed as

$$
\begin{aligned}
& \mathbf{Y}_{\mathbf{L}}=\mathbf{Z}_{\mathbf{L}}^{-1}=\left[\begin{array}{cc}
Z_{L d d} & Z_{L d q} \\
Z_{L q d} & Z_{L q q}
\end{array}\right]^{-1}=\left[\begin{array}{cc}
L s & -\omega L \\
\omega L & L s
\end{array}\right]^{-1} \\
& \mathbf{Z}_{\mathbf{C}}=\mathbf{Y}_{\mathbf{C}}^{-1}=\left[\begin{array}{cc}
Y_{C d d} & Y_{C d q} \\
Y_{C q d} & Y_{C q q}
\end{array}\right]^{-1}=\left[\begin{array}{cc}
C s & -\omega C \\
\omega C & C s
\end{array}\right]^{-1} \\
& \mathbf{G}_{\mathbf{c i}}=\left[\begin{array}{cc}
k_{p i}+k_{i i} / s & 0 \\
0 & k_{p i}+k_{i i} / s
\end{array}\right] \quad \mathbf{G}_{\mathbf{d e i}}=\left[\begin{array}{cc}
0 & -\omega_{0} L \\
\omega_{0} L & 0
\end{array}\right] \\
& \mathbf{G}_{\text {del }}=\left[\begin{array}{cc}
1 / 1+T_{\text {delay }} s & 0 \\
0 & 1 / 1+T_{\text {delay }} s
\end{array}\right] \\
& \mathbf{G}_{\mathbf{c v}}=\left[\begin{array}{cc}
k_{p v}+k_{i v} / s & 0 \\
0 & k_{p v}+k_{i v} / s
\end{array}\right] \quad \mathbf{G}_{\mathbf{d e v}}=\left[\begin{array}{cc}
0 & -\omega_{0} C \\
\omega_{0} C & 0
\end{array}\right]
\end{aligned}
$$




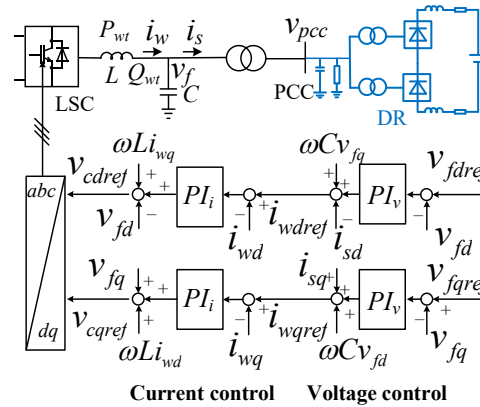

(a)

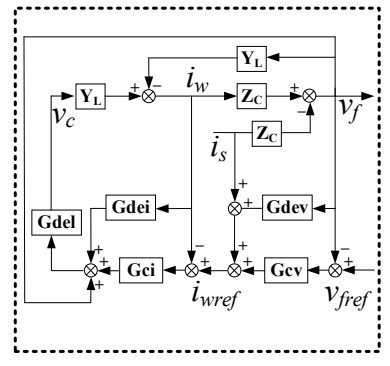

(b)
Fig. 5 (a) grid forming converter with voltage and current control; (b) smallsignal impedance converter model with voltage and current control.

B. WT LSC impedance modelling considering PLL based frequency control

To ensure distributed control of offshore WTs, a distributed PLL based WT frequency control was proposed in [20] by the authors, where an additional PLL based frequency loop is used for each WT to regulate the $q$-axis voltage reference $v_{\text {fqref }}$, as shown in Fig 6 (a). Fig. 6 (b) presents the small-signal impedance model when the PLL based frequency control is considered, and the corresponding output impedance is

$$
\begin{aligned}
Z_{v f} & =-Z_{C}\left(I-Y_{L} G_{d e l} G_{d e i}\right) \\
& \left(\begin{array}{l}
I-Y_{L} G_{d e l} G_{d e i}+Z_{C} Y_{L}+Y_{L} G_{d e l} G_{c i} \\
-Z_{C} Y_{L} G_{d e l} G_{c i} G_{d e v}+Z_{C} Y_{L} G_{d e l} G_{c i} G_{c v}-Z_{C} Y_{L} G_{d e l} \\
+G_{c i} G_{d e l} Y_{L} Z_{C} G_{c v}+G_{c i} G_{d e l} Y_{L} Z_{C} G_{P L L} G_{c f} G_{c v}
\end{array}\right)
\end{aligned}
$$

where the PLL control matrix $\mathbf{G}_{P L L}$ and the frequency control matrix $\mathbf{G}_{\mathbf{c f}}$ are expressed as

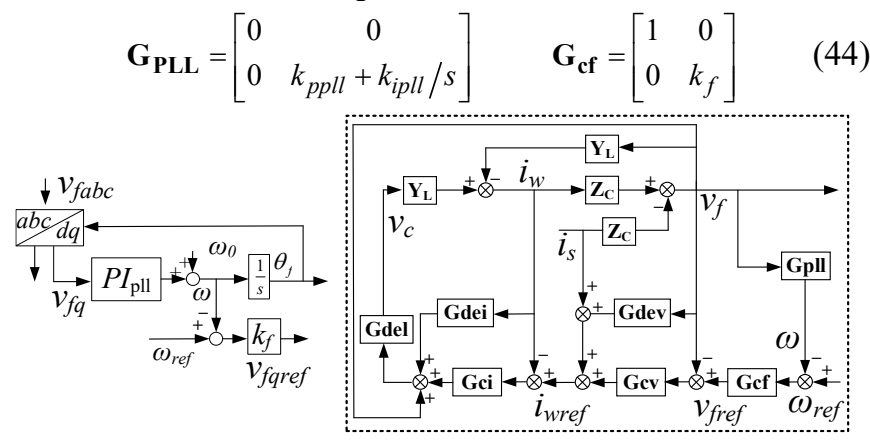

(a)

(b)

Fig. 6 (a) PLL based frequency control; (b) small-signal impedance model of the converter with PLL based frequency control, outer voltage control and inner current control.

\section{WT LSC impedance modelling considering power control}

Fig. 7 (a) presents the power control of WT LSC, where $P$ $V$ and $Q-f$ control is used to regulate the active and reactive power, respectively [14]. Although $P-f$ and $Q-V$ control is traditionally adopted for the synchronous generators in power system, these generators work on the load-following mode. During the load change, the generators adjust the power output to ensure the power balance between the sources and loads. In such way, the grid voltage and frequency are maintained in an acceptable value. However, for the DR-HVDC connected offshore system, all the generators (i.e. the offshore WTs) work on the maximum-power-point-tracking mode instead of loadfollowing mode. There are no load-following sources in this offshore system. If $P-f$ and $Q-V$ control is still adopted for these
WTs, the loads are suggested to work on the source-following mode (i.e. the loads vary according to the generated power). Such source-following mode can ensure the power balance between the generators and loads, meanwhile more importantly, ensure the offshore voltage and frequency are not significantly affected during the wind power change. However, when considering the DR-HVDC link as a 'special load', it is more like a constant load that cannot be easily adjusted to increase or decrease. Under such case, if $P-f$ and $Q-V$ control is still adopted for the WTs, the frequency of this isolated offshore system is the only variable that is used to regulate the active power absorbed by the DR-HVDC. Such scheme will lead to unacceptable offshore frequency change during the wind power increase from $0 \mathrm{pu}$ to $1 \mathrm{pu}$. On the other hand, if $P-V$ control is used for the WTs, during the wind power change, the offshore PCC voltage magnitude varies between $0.9 \mathrm{pu}$ to $1 \mathrm{pu}[8,14]$. Such voltage variation is acceptable for the offshore system. Thus, $P-V$ control is adopted for these DR-HVDC connected WTs. As the voltage magnitude is used for the WT active power regulation, $Q-f$ control is used to ensure the reactive power sharing among all the WTs $[14,19]$. The corresponding smallsignal impedance model after including the power control is shown in Fig. 7 (b) and its impedance is expressed as

$$
\begin{aligned}
& Z_{P Q}=-Z_{C}\left(I-Y_{L} G_{d e l} G_{d e i}+G_{c i} G_{d e l} Y_{L} G_{P Q i} G_{c P Q} G_{c f} G_{c v}\right) \\
& \left(\begin{array}{l}
I-Y_{L} G_{d e l} G_{d e i}+Z_{C} Y_{L}+Y_{L} G_{d e l} G_{c i} \\
-Z_{C} Y_{L} G_{d e l} G_{c i} G_{d e v}+Z_{C} Y_{L} G_{d e l} G_{c i} G_{c v}-Z_{C} Y_{L} G_{d e l} \\
+G_{c i} G_{d e l} Y_{L} Z_{C} G_{c v}+G_{c i} G_{d e l} Y_{L} Z_{C} G_{P L L} G_{c f} G_{c v} \\
+G_{c i} G_{d e l} Y_{L} G_{P Q i} G_{c P Q} G_{c f} G_{c v}+G_{c i} G_{d e l} Y_{L} G_{P Q v} G_{c P Q} G_{c f} G_{c v}
\end{array}\right)^{-1}
\end{aligned}
$$

where the power control matrix $\mathbf{G}_{\mathbf{c P Q}}$ and power calculation small signal matrix GPQv and GPQi are expressed as

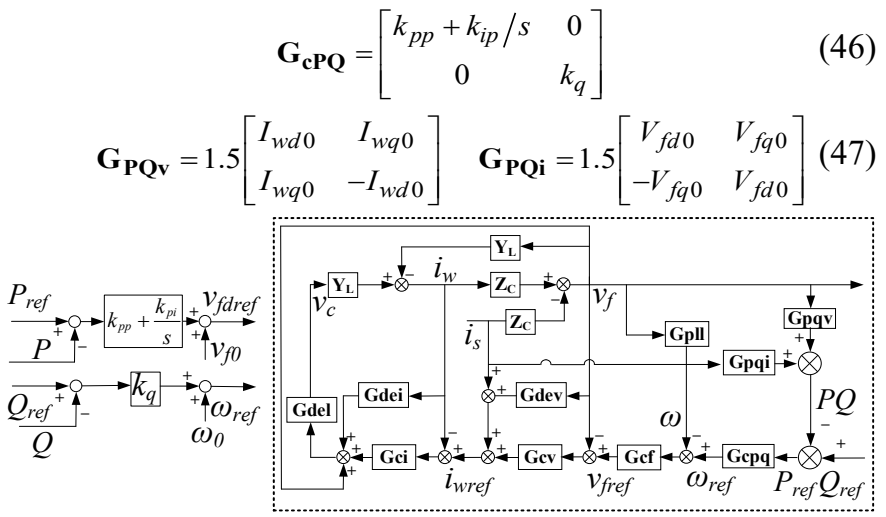

(a)

(b)

Fig. 7 (a) WT active power and reactive power control; (b) small-signal impedance model of the converter considering power control.

\section{WT LSC impedance modelling validation}

To validate the derived WT LSC impedance model, frequency scanning is also conducted in the time domain model in PSCAD/EMTDC. Fig. 8 compares the magnitudes and phases of the WT impedances (the WT transformer impedance is also included), where the red lines are the results from the established analytical model and the blue dots represent the frequency scanning results. As can be seen, the impedances from the analytical model are in excellent agreements with those from PSCAD/EMTDC simulation, validating the 
accuracy of the WT LSC analytical impedance modelling.
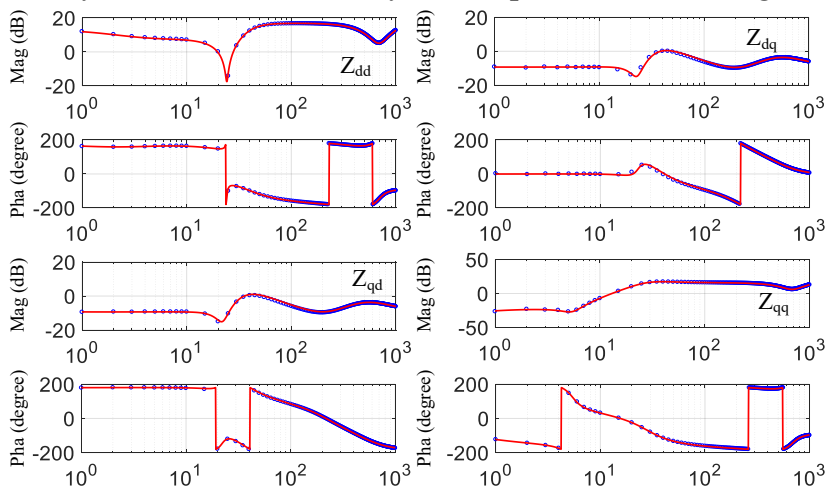

Fig. 8 WT LSC impedance modelling validation.

\section{StaBility ANALYSIS}

This section conducts stability analysis based on the derived impedance models, considering the change of DC smoothing reactors and $\mathrm{AC}$ filters (system parameters are presented in Appendix C). For the offshore station, the DC smoothing reactors and AC filters significant affect the weight, volume, and cost of the system, and are preferred to have small values from economic consideration [9, 24, 25]. In [25], the reactance of the total DC smoothing reactors is suggested to be $0.12 \mathrm{H}$ for a $1200 \mathrm{MW}$ DR-HVDC link, which is one tenth of $1.2 \mathrm{H}$ in the 1000 MW Cigre-benchmark LCC link model. In [9, 24], the AC filters are reduced from $446 \mathrm{MV}$ ar to $89 \mathrm{MVar}$ for a $1000 \mathrm{MW}$ DR-HVDC link, with the benefits of no filter switching, reduced installation costs and increased offshore station reliability. Meanwhile, $[9,24]$ also analyze the impacts of the reduced filter on offshore harmonics and reactive power balance, and conclude that such filter reduction has negligible impact on the harmonic distortion and reactive power can be properly balanced with the support from WT LSC. However, how does such design with significantly reduced DC reactors and AC filters affect the stability of the DR-HVDC connected offshore wind farms has not been thorough analyzed. In addition, this section also conducts the stability analysis considering the interaction between WTs.

\section{A. Principle of impedance-based stability analysis}

The small-signal impedance model of DR-HVDC connected WT is presented in Fig. 9, where $\mathbf{Z}_{\mathbf{W T}}$ is the WT impedance (including the WT transformer impedance) and $\mathbf{Y}_{\text {DR- }}$ HVDC is the admittance of the DR-HVDC (including the AC filters). With this small signal model, the current injected into the DR is expressed as

$$
I_{\text {DR }}=\frac{V_{W T}}{Z_{\text {DR-HVDC }}+Z_{W T}}=\frac{V_{W T}}{Z_{\text {DR-HVDC }}} \frac{I}{I+Z_{W T} Y_{\text {DR-HVDC }}}
$$

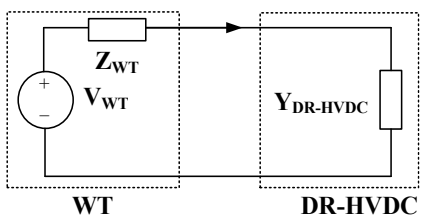

Fig. 9 Small-signal impedance model of DR-HVDC connected WT.

Considering the following conditions are usually satisfied: 1) the grid forming WT LSC is stable when not connected to DR; 2) the DR-HVDC is stable when connected to an ideal voltage source, the stability of this interconnected system is determined by $\mathbf{Z}_{\mathbf{W T}} \mathbf{Y}_{\text {DR-HVDC. }}$ If and only if $\mathbf{Z}_{\mathbf{W T}} \mathbf{Y}_{\text {DR-HVDC }}$ satisfies the Nyquist stability criterion, the current flowing into the DR is stable [26].

\section{B. Stability analysis with different DC smoothing reactors}

Fig. 10 shows the impacts of different DC smoothing reactance on the DR-HVDC output admittances (excluding DR AC side filters), with system operating at rated active power. As can be observed, when the DC reactance reduces from 0.6 $\mathrm{H}$ to $0.12 \mathrm{H}$, the phase of $\mathrm{Y}_{\mathrm{dd}}$ sees a significant change within $0-100 \mathrm{~Hz}$, while smaller DC reactance makes slower phase drop of $Y_{d d}$ to $-90^{\circ}$. On the other hand, the variation of DC reactance has negligible impact on $\mathrm{Y}_{\mathrm{qq}}$.
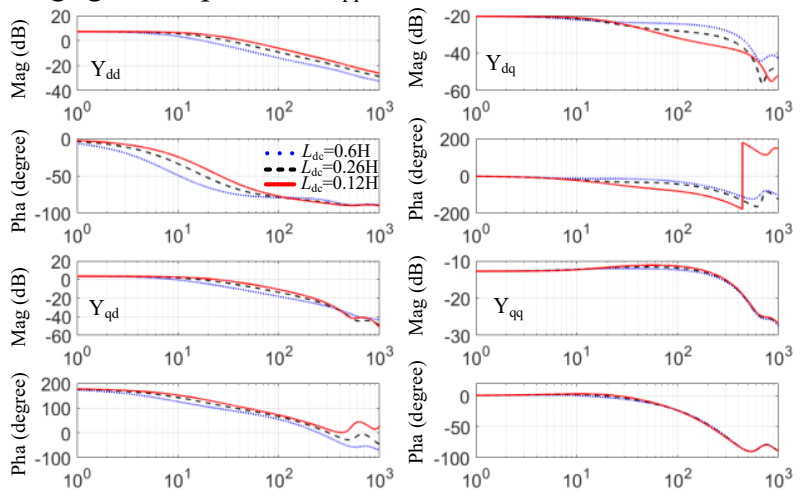

Fig. 10 DR-HVDC admittances with different DC smoothing reactance.

Fig. 11 presents the Nyquist plot of the $\mathrm{d}$ - and q-axis impedance ratios when the $\mathrm{DC}$ reactance is reduced from $0.6 \mathrm{H}$ to $0.12 \mathrm{H}$. As can be observed, the d-axis impedance ratio moves towards the point $(-1, \mathrm{j} 0)$ when the $\mathrm{DC}$ reactance initially reduces, while the q-axis impedance ratio does not have a large change and always satisfies the general Nyquist criteria. This phenomenon agrees with the observation from Fig. 10, as the DC reactance variation mainly affects the d-axis admittance. When the DC reactance is reduced to $0.26 \mathrm{H}$, the d-axis impedance ratio intersects with the unit circle at $30 \mathrm{~Hz}$, with phase margin reducing to $1^{\circ}$. With further reduction of the DC reactance to $0.12 \mathrm{H}$, the $\mathrm{d}$-axis impedance ratio encircles the point $(-1, j 0)$, resulting in instability of the interconnected system. Fig. 12 shows the WT generated active power and PCC current from time domain simulation for DC smoothing reactance of $0.26 \mathrm{H}$. Fourier analysis confirms that the WT active power experiences oscillation at around $30 \mathrm{~Hz}$, as predicted from the impedance model. Further time domain simulation also confirms that the system is unstable when the $\mathrm{DC}$ reactance is reduced to $0.12 \mathrm{H}$.

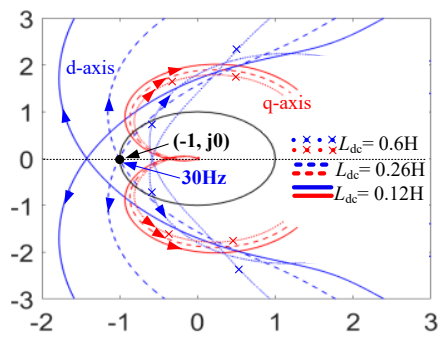

Fig. 11 Nyquist plot of the d-and q-axis impedance ratios when the DC reactance is reduced from $0.6 \mathrm{H}$ to $0.12 \mathrm{H}$. 

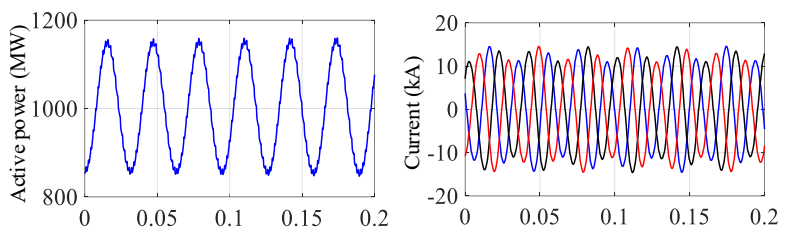

Fig. 12 WT generated active power and PCC current from time domain simulation with $0.26 \mathrm{H} \mathrm{DC}$ smoothing reactance.

To ensure the stability of the interconnected system when the DC reactance is reduced, the WT output impedances are reshaped through the modification of its control system (as it is difficult to modify the DR-HVDC output impedance due to its uncontrollability). Fig. 13 shows the Nyquist plots of the impedance ratios when the WT LSC dq voltage control bandwidth is increased from the initial value of $75 \mathrm{~Hz}$ to $92 \mathrm{~Hz}$, and then to $127 \mathrm{~Hz}$, with DC reactance of $0.12 \mathrm{H}$. As can be seen, when the voltage loop bandwidth is increased, the d-axis stability margin is significantly increased. Fig. 14 shows the time domain simulation results when the voltage control bandwidth is increased from $75 \mathrm{~Hz}$ to $127 \mathrm{~Hz}$ at $0.2 \mathrm{~s}$, demonstrating the interconnected system can operate stably with voltage control bandwidth at $127 \mathrm{~Hz}$ with a small DC reactance of $0.12 \mathrm{H}$. The stability of the interconnected system with increased voltage bandwidth is further investigated at other operating points (WT generates $0.5 \mathrm{pu}$ and $0.1 \mathrm{pu}$ active power, respectively) with $0.12 \mathrm{H}$ DC reactance. Nyquist plot in Fig. 15 demonstrates the system can operate stably at all these operation points, which is also confirmed by the time domain simulation.

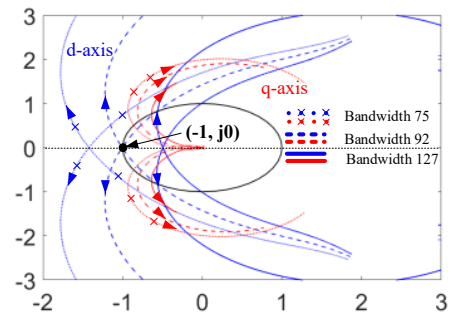

Fig. 13 Nyquist plot of the d- and q-axis impedance ratio when voltage bandwidth is increased from $75 \mathrm{~Hz}$ to $127 \mathrm{~Hz}$.
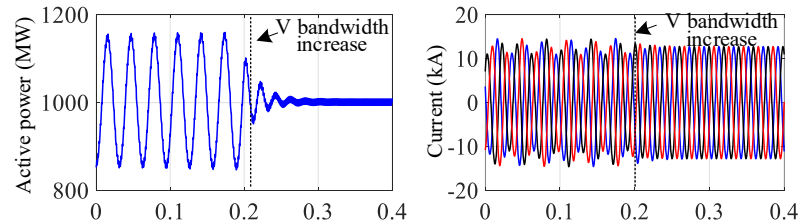

Fig. 14 WT generated active power and PCC current from time domain simulation when voltage control bandwidth is increased from $75 \mathrm{~Hz}$ to $127 \mathrm{HZ}$.

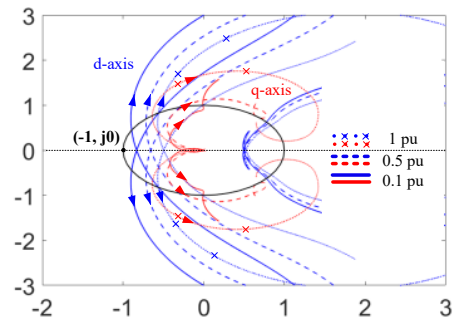

Fig. 15 Nyquist plots of the impedance ratios with increased voltage bandwidth at different operating point.

\section{Stability analysis with different AC filters}

Fig. 16 shows the DR-HVDC admittance when the AC filters reduce from 400 MVar to 100 MVar with system operating at rated active power (DC reactance is $0.12 \mathrm{H}$ and voltage control bandwidth is $127 \mathrm{~Hz}$ ). The reactive power required by the DR will be automatically provided by the WTs due to the use of $Q-f$ droop control. As can be observed, the AC filter reduction has a minor impact on $\mathrm{Y}_{\mathrm{dd}}$ below $100 \mathrm{~Hz}$, indicating the d-axis stability margin is largely not affected (as the d-axis impedance ratio intersects with the unit circle at low frequency range, which is the critical frequency range for stability consideration). On the other hand, the reduction of $\mathrm{AC}$ filters has a significant impact on the phase of $\mathrm{Y}_{\mathrm{qq}}$ above $50 \mathrm{~Hz}$.
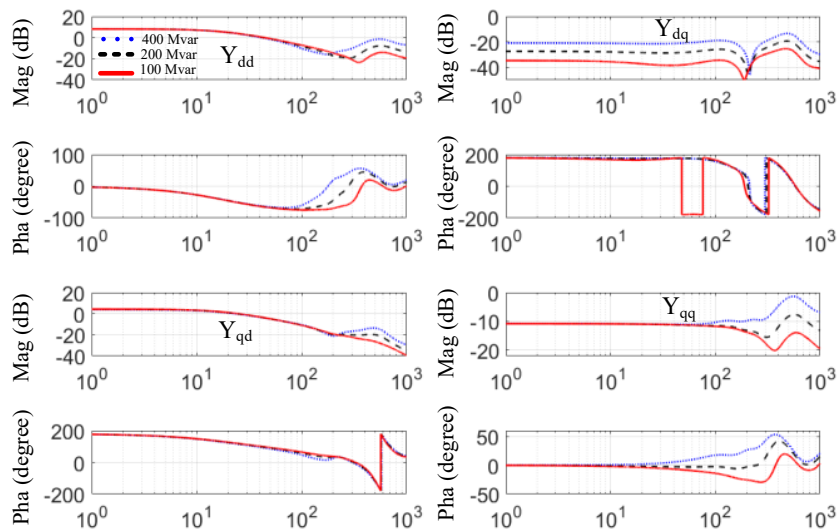

Fig. 16 Admittance with different AC filters (400 MVar, 200MVar and 100MVar respectively).

Fig. 17 (a) shows the Nyquist plot of the d- and q-axis impedance ratios when the $\mathrm{AC}$ filters are decreased from 400 MVar to 100 MVar at rated active power generation. As can be observed, with the decrease of AC filters, the q-axis impedance ratio moves away from the point $(-1, \mathrm{j} 0)$, indicating the increase of stability margin. On the other hand, the d-axis impedance ratio does not see a significant change around its intersection point. Fig. 17 (b) shows the Nyquist plot of the d- and q-axis impedance ratios with the same three filter sizes when the system operates at half rated active power generation. As seen, when the AC filters are 400 MVar at this operating point (241 MVar excessive reactive power is absorbed by the WT LSC), the q-axis impedance ratio intersects with the unit circle at 81 $\mathrm{Hz}$, with the phase margin at $8^{\circ}$. When the $\mathrm{AC}$ filters are at 200 MVar or 100 MVar, the q-axis stability margin is significantly increase. Fig. 18 shows the corresponding WT generated active power and PCC current from time domain simulation, when the filters are reduced from $400 \mathrm{Mvar}$ to $200 \mathrm{MVar}$ at $0.2 \mathrm{~s}$. As can be seen, the WT oscillation is eliminated after the AC filter decrease.

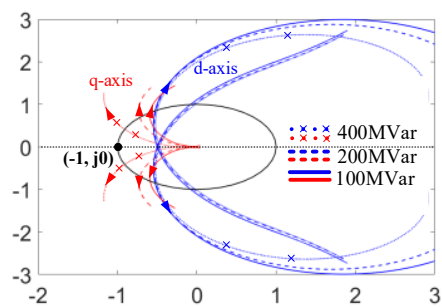

(a)

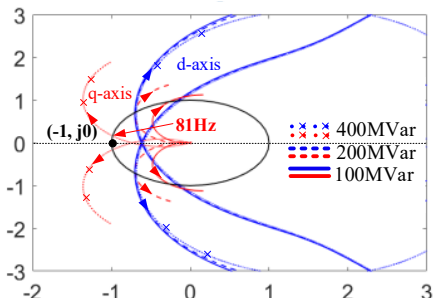

(b)
Fig. 17 Nyquist plots of d- and q-axis ratios when filters are reduced from 400 MVar to 100 MVar: (a) at rated active power; (b) at half rated active power. 

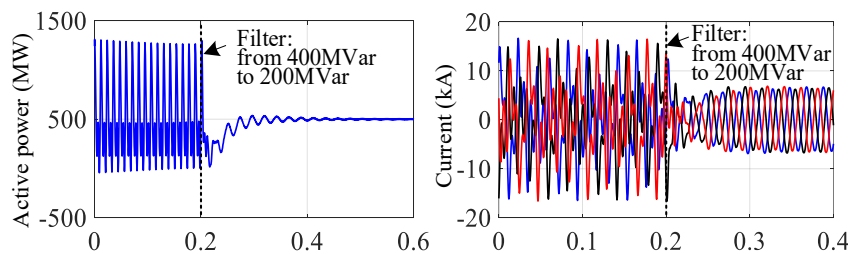

Fig. 18 WT generated active power and PCC current when filters are decreased from 400 Mvar to 200 Mvar at half the rated active power generation.

The impact of filters change on the system stability is further investigated when the WT generates 0.1 pu active power. Fig. 19 shows the Nyquist plot of the impedance ratios at this operation point, when the AC filters are at 400, 200 and 100 MVar, respectively. As seen, when the AC filters are $400 \mathrm{MVar}$ (WT LSC absorbs 350 MVar reactive power), the q-axis impedance ratio encircles the point $(-1, j 0)$, demonstrating an unstable WT-HVDC system. Time domain simulation also confirms the system is unstable when 400 Mvar filter is connected at this operating point. When the AC filters are 200 MVar or 100 MVar, both the Nyquist plot and time domain simulation show the WT-HVDC interconnected system operates stably.

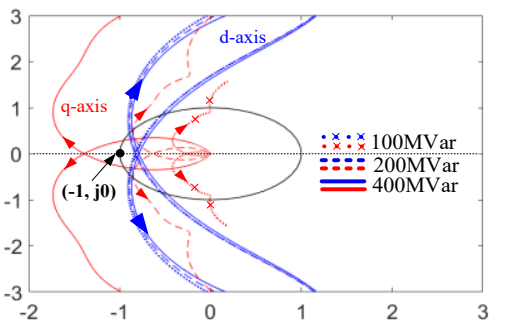

Fig. 19 Nyquist plot of the d-and q-axis impedance ratios when the AC filters are decreased from $400 \mathrm{MVar}$ to $100 \mathrm{MVar}$ at 0.1 p.u. active power generation.

According to the analysis conducted in subsection B and this subsection, it can be concluded that

- Smaller DC reactance can contribute to reducing the weight, value and cost of offshore station, but pose challenges on daxis stability of the WT-HVDC interconnected system. Faster offshore voltage control of WT LSC is a way to minimize such instability potential.

- In contrast to that small DC reactance degrades d-axis stability margin, small sizes of AC filters lead to increased qaxis stability margin. Thus, when considering the stability of WT-HVDC interconnected system, and offshore station weight/volume/cost, small sizes of AC filters are suggested, if the harmonic filtering and reactive power compensation requirements are satisfied.

\section{Stability analysis considering the interaction between WTS}

This subsection conducts the stability analysis considering the interaction between WTs. The offshore wind farms are thus modelled as: ten $10 \mathrm{MW}$ WTs representing one detailed WT string, an aggregated $300 \mathrm{MW}$ WT and an aggregated $600 \mathrm{MW}$ WT, as shown in Fig. 20. The studied offshore wind farms are considered as two subsystems from the connection point $\mathrm{C}_{-} 12$, i.e. WT1 as the first subsystem while the other WTs and DRHVDC as the second subsystem. The corresponding smallsignal impedance model of the system is presented in Fig. 21. The stability of this interconnected system is thus determined by $\mathbf{Z}_{\mathbf{W T 1}} \mathbf{Y}_{\text {eq }}$, where $\mathbf{Y}_{\text {eq }}$ is the equivalent admittance of the other
WTs and DR-HVDC (Note that $\mathbf{Y}_{\mathbf{W T i}}(\mathrm{i}=2,3 \ldots .10,300,600)$ are the admittances after transferring from the local dq frame to the global dq frame). If and only if $\mathbf{Z}_{\mathbf{W T}} \mathbf{Y}_{\text {eq }}$ satisfies the Nyquist stability criterion, the current of WT1 is stable.

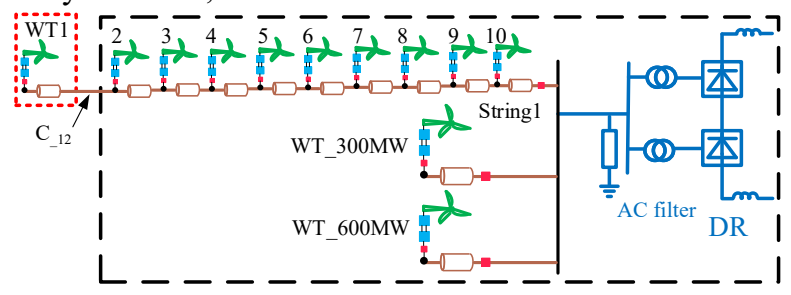

Fig. 20 DR-HVDC connected offshore wind farms.

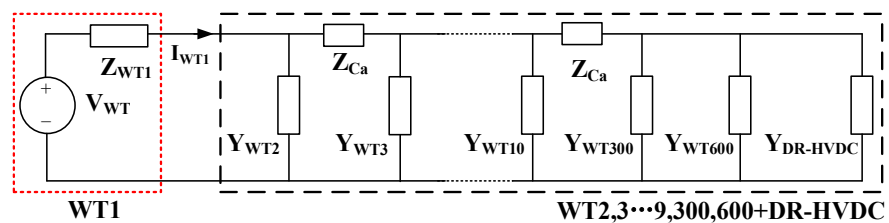

Fig. 21 Small-signal impedance model of WT1 and other WTs connected to DR-HVDC.

Fig. 22 shows the d-and q-axis impedances of WT1 which operates at rated power. It demonstrates that the WT has a lowfrequency resonance point in the d-axis impedance. As the $P-V$ control plays an important role in determining the impedance in such frequency range, the impact of the WT $P-V$ control on the system stability is analyzed. Fig. 23 shows the Nyquist plot of the $\mathrm{d}$ - and q-axis impedance ratios when the proportional gain of the $P-V$ control $k_{p p}$ decreases from $0.3043 \mathrm{pu}$ to $0.3002 \mathrm{pu}$. As observed, with the decrease of $k_{p p}$, the d-axis impedance ratio moves towards to the point $(-1, \mathrm{j} 0)$, indicating the decrease of stability margin. When $k_{p p}$ is decreased to $0.3015 \mathrm{pu}$, the daxis impedance ratio intersects with the unit circle at $15.9 \mathrm{~Hz}$, with the phase margin at $1^{\circ}$. Fig. 24 shows the corresponding time-domain WT1 generated active power and WT1 current, when $k_{p p}$ is 0.3021 pu during $0-0.5 \mathrm{~s}$. Fourier analysis confirms that the WT active power experiences oscillation at around 16 $\mathrm{Hz}$, as predicted from the impedance model. When the proportional gain of the $P-V$ control $k_{p p}$ is increased to 0.3043 pu at $0.5 \mathrm{~s}$, the WT oscillation is effectively eliminated, as shown in Fig. 24.
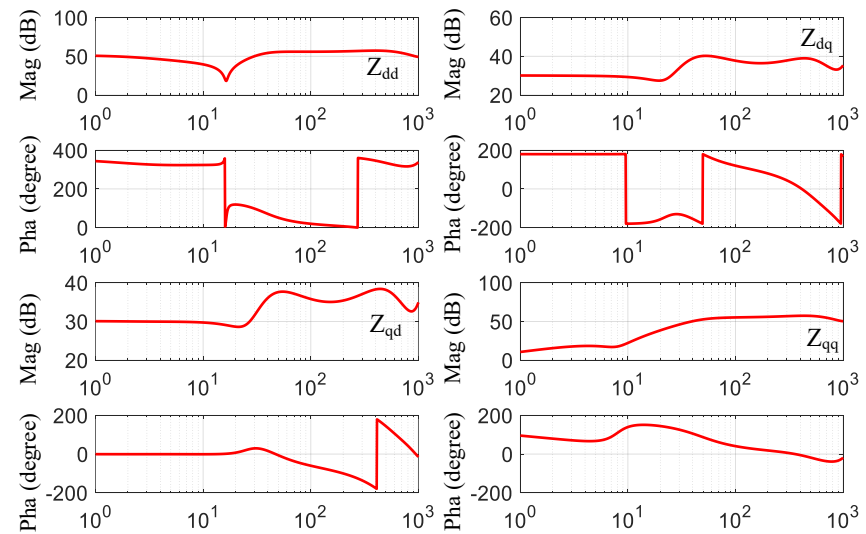

Fig. 22 WT1 d- and q-axis impedance.

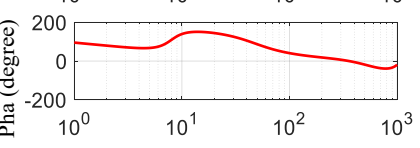




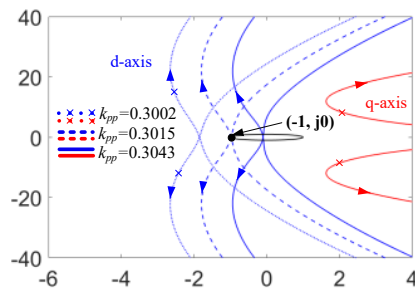

Fig. 23 Nyquist plot of the d- and q-axis impedance ratio when $k_{p p}$ decreases from 0.3043 pu to $0.3002 \mathrm{pu}$.
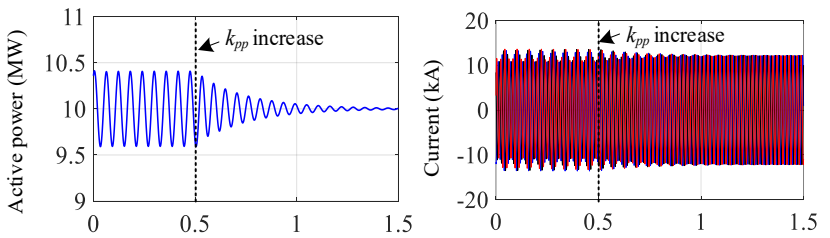

Fig. 24 WT1 generated active power and current when $k_{p p}$ are increased from 0.3021 pu to 0.3043 pu at $0.5 \mathrm{~s}$.

To further investigate the interaction between WTs, stability analysis is conducted considering different operating points. Fig. 25 shows the Nyquist plot of the d- and q-axis impedance ratios when the WTs generate $1 \mathrm{pu}, 0.5 \mathrm{pu}$ and 0.2 $\mathrm{pu}$ active power (the proportional gain of the active power control $k_{p p}$ is set as $0.3043 \mathrm{pu}$ ). As can be seen, with the decrease of generated active power, the d-axis impedance ratio moves towards to the point $(-1, \mathrm{j} 0)$, demonstrating the decrease of stability margin, while the q-axis impedance ratio sees a little change. When the WTs generate 0.2 pu active power, the d-axis impedance ratio encircles the point $(-1, j 0)$, representing the instability of the system. Fig. 26 shows the WT1 generated active power from time domain simulation, when it is increased from $0.2 \mathrm{pu}(2 \mathrm{MW})$ to $0.5 \mathrm{pu}(5 \mathrm{MW})$ during 1-2.5 s. As seen, the WT oscillation is eliminated gradually when the WT operates at $0.5 \mathrm{pu}$, which is in agreement with the small signal analysis.

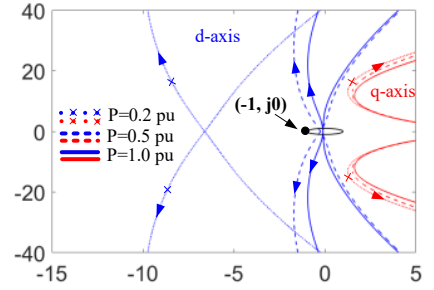

Fig. 25 Nyquist plot of the d- and q-axis impedance ratio when the WTs generate $1 \mathrm{pu}, 0.5 \mathrm{pu}$ and $0.2 \mathrm{pu}$ active power.

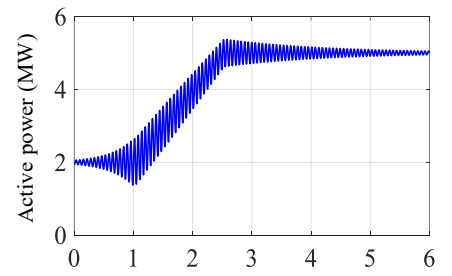

Fig. 26 WT1 generated active power.

Fig. 27 shows the Nyquist plot of the $d$ - and q-axis impedance ratios when the proportional gain of the active power control $k_{p p}$ increases from $0.3043 \mathrm{pu}$ to $0.3136 \mathrm{pu}$ (with all WTs operating at 0.2 pu active power). As can be seen, when $k_{p p}$ is increased to $0.3118 \mathrm{pu}$, the d-axis impedance ratio intersects with the unit circle at $16.3 \mathrm{~Hz}$, with the phase margin at $6^{\circ}$. When $k_{p p}$ is further increased to $0.3136 \mathrm{pu}$, the phase margin of the $d$-axis impedance ratio is increased to $80^{\circ}$. On the other hand, the q-axis impedance ratio almost keeps unchanged and always satisfies the general Nyquist criteria during the variation of the $k_{p p}$. Time-domain simulation confirms that WTs operate stably when $k_{p p}$ is increased to $0.3136 \mathrm{pu}$.

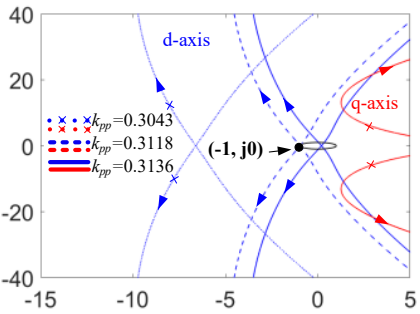

Fig. 27 Nyquist plot of the d- and q-axis impedance ratio when $k_{p p}$ increases from $0.3118 \mathrm{pu}$ to $0.3136 \mathrm{pu}$.

\section{CONCLUSION}

This paper develops an impedance model of DR-HVDC connected offshore wind farm. The analytical impedance is verified by the frequency scanning results from time-domain simulation model in PSCAD/EMTDC. Based on the derived impedance model, stability analysis is conducted considering the variations of the sizes of DC smoothing reactors and $\mathrm{AC}$ filters. It shows that reduced DC smoothing reactance degrades the stability of the interconnected system. Faster voltage control is a potential way to mitigate the problem and increase its stability margin under such cases. In addition, the analysis also shows that reduced AC filters help to increase the system stability margin, although the selection also needs to consider the harmonic filtering and reactive power compensation requirements. Moreover, stability analysis considering the interaction between WTs reveals that the WT $P-V$ control has a significant impact on the stability of the DR-HVDC connected WTs. Increased proportional gain of WT $P-V$ control can help improve system stability.

\section{ACKNOWLEDGEMENT}

We thank Dr. Yi Qi for useful discussion during the impedance modelling.

\section{REFERENCE}

[1] J. Liang, T. Jing, O. Gomis-Bellmunt, J. Ekanayake, and N. Jenkins, "Operation and Control of Multiterminal HVDC Transmission for Offshore Wind Farms," IEEE Transactions on Power Delivery, vol. 26, pp. 2596-2604, 2011.

[2] P. Bresesti, W. L. Kling, R. L. Hendriks, and R. Vailati, "HVDC Connection of Offshore Wind Farms to the Transmission System," IEEE Transactions on Energy Conversion, vol. 22, pp. 37-43, 2007.

[3] A. Abdalrahman and E. Isabegovic, "DolWin1 - Challenges of connecting offshore wind farms," in 2016 IEEE International Energy Conference (ENERGYCON), 2016, pp. 1-10.

[4] C. Buchhagen, C. Rauscher, A. Menze, and J. Jung, "BorWin1 - First Experiences with harmonic interactions in converter dominated grids," in International ETG Congress 2015; Die Energiewende - Blueprints for the new energy age, 2015, pp. 1-7.

[5] C. Buchhagen, M. Greve, A. Menze, and J. Jung, "Harmonic stabilitypractical experience of a TSO," in Proc. Wind Integr. Workshop, 2016, pp. $1-6$.

[6] M. Amin and M. Molinas, "Understanding the Origin of Oscillatory Phenomena Observed Between Wind Farms and HVdc Systems," IEEE Journal of Emerging and Selected Topics in Power Electronics, vol. 5, pp. 378-392, 2017.

[7] J. Lyu, X. Cai, and M. Molinas, "Frequency Domain Stability Analysis of MMC-Based HVdc for Wind Farm Integration," IEEE Journal of Emerging and Selected Topics in Power Electronics, vol. 4, pp. 141-151, 2016. 
This paper is a post-print of a paper submitted to and accepted for publication in IEEE Transaction on Power Delivery and is subject to Institution of

[8] R. Blasco-Gimenez, S. A.-. Villalba, J. Rodríguez-D'Derlée, F. Morant, and S. Bernal-Perez, "Distributed Voltage and Frequency Control of Offshore Wind Farms Connected With a Diode-Based HVdc Link," IEEE Transactions on Power Electronics, vol. 25, pp. 3095-3105, 2010.

[9] R. Blasco-Gimenez, N. Aparicio, S. Ano-Villalba, and S. Bernal-Perez, "LCC-HVDC Connection of Offshore Wind Farms With Reduced Filter Banks," IEEE Transactions on Industrial Electronics, vol. 60, pp. 23722380, 2013.

[10] A. Bidadfar, O. Saborio-Romano, N. A. Cutululis, and P. E. Sorensen, "Control of Offshore Wind Turbines Connected to Diode-Rectifier-Based HVdc Systems," IEEE Transactions on Sustainable Energy, pp. 1-1, 2020.

[11] O. Kuhn, P. Menke, R. Zurowski, T. Christ, S. Seman, and G. Giering, "2nd generation DC grid access for offshore wind farms: HVDC in an AC fashion," CIGRE, Paris, pp. 1-7, 2016.

[12] T. Hammer, S. Seman, P. Menke, F. Hacker, B. Szangolies, J. Meth, et al., "Diode-rectifier HVDC link to onshore power systems: Dynamic performance of wind turbine generators and reliability of liquid immersed HVDC diode rectifier units," in CIGRE Conference Technical Committee B4, 2016.

[13] R. Ramachandran, S. Poullain, A. Benchaib, S. Bacha, and B. Francois, "On the Black Start of Offshore Wind Power Plants with Diode Rectifier based HVDC Transmission," in 201921 st European Conference on Power Electronics and Applications (EPE'19 ECCE Europe), 2019, pp. P.1-P.10.

[14] L. Yu, R. Li, and L. Xu, "Distributed PLL-Based Control of Offshore Wind Turbines Connected With Diode-Rectifier-Based HVDC Systems," IEEE Transactions on Power Delivery, vol. 33, pp. 1328-1336, 2018.

[15] C. Prignitz, H. Eckel, and H. Knaak, "Voltage and current behavior in a FixReF controlled offshore wind farm using a HVDC transmission system based on uncontrolled diode rectifier units," in 2016 18th European Conference on Power Electronics and Applications (EPE'16 ECCE Europe), 2016, pp. 1-6.

[16] M. Á. Cardiel-Álvarez, S. Arnaltes, J. L. Rodriguez-Amenedo, and A. Nami, "Decentralized Control of Offshore Wind Farms Connected to Diode-Based HVdc Links," IEEE Transactions on Energy Conversion, vol. 33, pp. 1233-1241, 2018.

[17] M. Á. Cardiel-Álvarez, J. L. Rodriguez-Amenedo, S. Arnaltes, and M. E. Montilla-DJesus, "Modeling and Control of LCC Rectifiers for Offshore Wind Farms Connected by HVDC Links," IEEE Transactions on Energy Conversion, vol. 32, pp. 1284-1296, 2017.

[18] O. Saborio-Romano, A. Bidadfar, J. N. Sakamuri, L. Zeni, O. Goksu, and N. A. Cutululis, "Communication-Less Frequency Support from Offshore Wind Farms Connected to HVdc via Diode Rectifiers," IEEE Transactions on Sustainable Energy, pp. 1-1, 2020.

[19] L. Yu, R. Li, L. Xu, and G. P. Adam, "Analysis and Control of Offshore Wind Farms Connected With Diode Rectifier-Based HVDC System," IEEE Transactions on Power Delivery, vol. 35, pp. 2049-2059, 2020.

[20] H. Huang, C. Mao, J. Lu, and D. Wang, "Small-signal modelling and analysis of wind turbine with direct drive permanent magnet synchronous generator connected to power grid," IET Renewable Power Generation, vol. 6, pp. 48-58, 2012.

[21] H. Liu and J. Sun, "Voltage Stability and Control of Offshore Wind Farms With AC Collection and HVDC Transmission," IEEE Journal of Emerging and Selected Topics in Power Electronics, vol. 2, pp. 11811189, 2014.

[22] E. V. Larsen, D. H. Baker, and J. C. McIver, "Low-order harmonic interactions on AC/DC systems," IEEE Transactions on Power Delivery, vol. 4, pp. 493-501, 1989.

[23] Y. Qi, H. Zhao, S. Fan, A. M. Gole, H. Ding, and I. T. Fernando, "Small Signal Frequency-Domain Model of a LCC-HVDC Converter Based on an Infinite Series-Converter Approach," IEEE Transactions on Power Delivery, vol. 34, pp. 95-106, 2019.

[24] R. Blasco-Gimenez, S. A.-. Villalba, N. Aparicio, and S. Bernal-Perez, "Harmonic filter reduction of off-shore wind farms connected with a diode based HVDC link," in 2012 IEEE International Symposium on Industrial Electronics, 2012, pp. 1585-1590.

[25] S. Seman, N. Tuan Trinh, R. Zurowski, and S. Kreplin, Modeling of the Diode-Rectifier Based HVDC Transmission Solution for Large Offshore Wind Power Plants Grid Access, 2016.

[26] J. Sun, "Impedance-Based Stability Criterion for Grid-Connected Inverters," IEEE Transactions on Power Electronics, vol. 26, pp. 30753078, 2011.

\section{APPENDIX}

\section{A. Commutation overlap angle dynamics}

$$
\begin{aligned}
\frac{\Delta \mu}{\Delta v_{d}} & =G_{11} \frac{\Delta \mu}{\Delta i_{2 d}}+G_{21} \frac{\Delta \mu}{\Delta i_{2 q}} \\
& =\frac{\omega_{0}\left(-s \sin \mu_{0}+\omega_{0} \cos \mu_{0}-\omega_{0} e^{-s \mu_{0} / \omega_{0}}\right)}{\left(s^{2}+\omega_{0}^{2}\right)\left(v_{d 0} \sin \mu_{0}+v_{q 0} \cos \mu_{0}\right)} \\
\frac{\Delta \mu}{\Delta v_{q}} & =G_{12} \frac{\Delta \mu}{\Delta i_{2 d}}+G_{22} \frac{\Delta \mu}{\Delta i_{2 q}} \\
& =\frac{\omega_{0}\left(-s \cos \mu_{0}-\omega_{0} \sin \mu_{0}+s e^{\left.-s \mu_{0} / \omega_{0}\right)}\right.}{\left(s^{2}+\omega_{0}^{2}\right)\left[v_{d 0} \sin \left(\mu_{0}\right)+v_{q 0} \cos \left(\mu_{0}\right)\right]} \\
\frac{\Delta \mu}{\Delta I_{d c}} & =\frac{\left(1+e^{\left.-s \mu_{0} / \omega_{0}\right) \omega_{0} L_{c}}\right.}{\sqrt{3}\left[v_{d 0} \sin \left(\mu_{0}\right)+v_{q 0} \cos \left(\mu_{0}\right)\right]}
\end{aligned}
$$

B. Diode rectifier AC current dynamics

$$
\begin{aligned}
& K_{11}=\frac{\Delta i_{d}}{\Delta v_{d}}=\frac{\Delta i_{d}^{c}+\Delta i_{d}^{n c}}{\Delta v_{d}}=G_{11} \frac{\Delta i_{d}}{\Delta i_{2 d}}+G_{21} \frac{\Delta i_{d}}{\Delta i_{2 q}} \\
& =\frac{3}{4 \pi L_{c}\left(s^{2}+\omega_{0}^{2}\right)}\left[-s \sin 2 \mu+2 \mu s+\omega_{0} \cos 2 \mu-\omega_{0}\right. \\
& \left.+\frac{4 \omega_{0}^{3}-4 \omega_{0}^{2}\left(\omega_{0} \cos \mu_{0}+s \sin \mu_{0}\right) e^{-s \mu_{0} / \omega_{0}}}{\left(s^{2}+\omega_{0}^{2}\right)}\right] \\
& K_{12}=\frac{\Delta i_{d}}{\Delta v_{q}}=G_{12} \frac{\Delta i_{d}}{\Delta i_{2 d}}+G_{22} \frac{\Delta i_{d}}{\Delta i_{2 q}} \\
& =\frac{3}{4 \pi L_{c}\left(s^{2}+\omega_{0}^{2}\right)}\left[-s \cos 2 \mu+s-\omega_{0} \sin 2 \mu+2 \omega_{0} \mu\right. \\
& \left.-\frac{\left.4 \omega_{0}^{2} s-4 \omega_{0} s\left(\omega_{0} \cos \mu_{0}+s \sin \mu_{0}\right) e^{-s \mu_{0} / \omega_{0}}\right]}{\left(s^{2}+\omega_{0}^{2}\right)}\right] \\
& K_{13}=\frac{\Delta i_{d}}{\Delta I_{d c}}=\frac{2 \sqrt{3}}{\pi}\left[\frac{1+\cos \mu}{2}\right. \\
& \left.-\frac{\omega_{0}^{2}-\omega_{0}\left(\omega_{0} \cos \mu_{0}+s \sin \mu_{0}\right) e^{-s \mu_{0} / \omega_{0}}}{2\left(s^{2}+\omega_{0}^{2}\right)}\right] \\
& K_{21}=\frac{\Delta i_{q}(s)}{\Delta v_{d}}=G_{11} \frac{\Delta i_{q}}{\Delta i_{2 d}}+G_{21} \frac{\Delta i_{q}}{\Delta i_{2 q}} \\
& =\frac{3}{4 \pi L_{c}\left(s^{2}+\omega_{0}^{2}\right)}\left[-s \cos (2 \mu)+s-\omega_{0} \sin (2 \mu)\right. \\
& \left.-2 \mu \omega_{0}+\frac{4 \omega_{0}^{2} s-4 \omega_{0}^{2}\left(s \cos \mu-\omega_{0} \sin \mu\right) e^{-s \mu_{0} / \omega_{0}}}{\left(s^{2}+\omega_{0}^{2}\right)}\right] \\
& K_{22}=\frac{\Delta i_{q}(s)}{\Delta v_{q}}=G_{12} \frac{\Delta i_{q}}{\Delta i_{2 d}}+G_{22} \frac{\Delta i_{q}}{\Delta i_{2 d}} \\
& =\frac{3}{4 \pi L_{c}\left(s^{2}+\omega_{0}{ }^{2}\right)}\left[s \sin (2 \mu)+2 \mu s-\omega_{0} \cos (2 \mu)\right. \\
& \left.+\omega_{0}-\frac{4 \omega_{0} s^{2}-4 \omega_{0} s\left(s \cos \mu-\omega_{0} \sin \mu\right) e^{-s \mu_{0} / \omega_{0}}}{\left(s^{2}+\omega_{0}^{2}\right)}\right]
\end{aligned}
$$




$$
\begin{aligned}
K_{23}= & \frac{\Delta i_{q}(s)}{\Delta I_{d c}(s)}=\frac{2 \sqrt{3}}{\pi}\left[-\frac{\sin \mu}{2}\right. \\
& \left.-\frac{\omega_{0} s-\omega_{0}\left(s \cos \mu-\omega_{0} \sin \mu\right) e^{-s \mu_{0} / \omega_{0}}}{2\left(s^{2}+\omega_{0}^{2}\right)}\right]
\end{aligned}
$$

C. Parameters of the tested DR-HVDC system

\begin{tabular}{|c|c|c|c|}
\hline & Par: & eters & Values \\
\hline \multirow{12}{*}{ DR-HVDC } & \multicolumn{2}{|c|}{$\begin{array}{c}\text { Rated Power \& } \\
\text { DC voltage }\end{array}$} & $1000 \mathrm{MW} ; \pm 320 \mathrm{kV}$ \\
\hline & \multicolumn{2}{|c|}{ DR Transformer } & $66 \mathrm{kV} / 261.8 \mathrm{kV} / 261.8 \mathrm{kV} ; 0.18 \mathrm{pu}$ \\
\hline & \multicolumn{2}{|c|}{ DC reactors } & $0.6 \mathrm{H} / 0.26 \mathrm{H} / 0.12 \mathrm{H}$ \\
\hline & \multirow{9}{*}{ Filters } & \multirow{3}{*}{$\begin{array}{l}400 \\
\text { MVar }\end{array}$} & $\mathrm{C}_{1}: 58.489 \mu \mathrm{F}$ \\
\hline & & & $\begin{array}{c}\mathrm{C}_{2}: 116.98 \mu \mathrm{F} ; \mathrm{C}_{3}: 1300 \mu \mathrm{F} ; \\
\mathrm{L}_{1}: 7.8 \mathrm{mH} ; \mathrm{R}_{1}: 1.70 \Omega ; \mathrm{R}_{2}: 14.97 \Omega\end{array}$ \\
\hline & & & $\mathrm{C}_{4}: 116.98 \mu \mathrm{F} ; \mathrm{L}_{2}: 0.78 \mathrm{mH} ; \mathrm{R}_{3}: 4.76 \Omega$ \\
\hline & & \multirow{3}{*}{$\begin{array}{l}200 \\
\text { MVar }\end{array}$} & $29.2445 \mu \mathrm{F}$ \\
\hline & & & $\begin{array}{c}58.49 \mu \mathrm{F} ; 650 \mu \mathrm{F} ; \\
15.6 \mathrm{mH} ; 3.40 \Omega ; 29.94 \Omega\end{array}$ \\
\hline & & & $58.49 \mu \mathrm{F} ; 1.55 \mathrm{mH} ; 9.52 \Omega$ \\
\hline & & \multirow{3}{*}{$\begin{array}{l}100 \\
\text { MVar }\end{array}$} & $14.6222 \mu \mathrm{F}$ \\
\hline & & & $\begin{array}{c}29.2445 \mu \mathrm{F} ; 325 \mu \mathrm{F} ; \\
31.2 \mathrm{mH} ; 6.80 \Omega ; 59.88 \Omega\end{array}$ \\
\hline & & & $29.24 \mu \mathrm{F} ; 3.11 \mathrm{mH} ; 19.05 \Omega$ \\
\hline \multirow{4}{*}{ WT LSC } & \multicolumn{2}{|c|}{ Rated power } & $1000 \mathrm{MW}$ \\
\hline & \multicolumn{2}{|c|}{ WT Transformer } & $0.69 \mathrm{kV} / 66 \mathrm{kV} ; 0.08 \mathrm{pu}$ \\
\hline & \multicolumn{2}{|c|}{ Line reactance } & $0.1 \mathrm{pu}$ \\
\hline & \multicolumn{2}{|c|}{ Filter capacitor } & $0.05 \mathrm{pu}$ \\
\hline \multirow{4}{*}{$\begin{array}{l}\text { WT LSC } \\
\text { control }\end{array}$} & \multicolumn{2}{|c|}{$P Q$ control } & $\begin{array}{c}k_{p p}: 0.334 \mathrm{pu} \\
k_{i p}: 18.56 \mathrm{pu} ; k_{q}: 0.032 \mathrm{pu}\end{array}$ \\
\hline & \multicolumn{2}{|c|}{$\begin{array}{c}\text { PLL based } \\
\text { frequency control }\end{array}$} & $\begin{array}{c}k_{p p l l}: 0.6 \mathrm{pu} ; k_{\text {ipll }}: 28.3 \mathrm{pu} \\
k_{f}: 0.077 \mathrm{pu}\end{array}$ \\
\hline & \multicolumn{2}{|c|}{ Voltage control } & $\begin{array}{c}k_{p v}: 0.12 \mathrm{pu} ; k_{i v}: 22.62 \mathrm{pu} \\
\text { bandwidth: } 75 \mathrm{~Hz}\end{array}$ \\
\hline & \multicolumn{2}{|c|}{ Current control } & $\begin{array}{l}k_{p i}: 0.4 \mathrm{pu} ; k_{i i}: 0 \mathrm{pu} ; \\
\text { bandwidth: } 300 \mathrm{~Hz}\end{array}$ \\
\hline
\end{tabular}

Table I Parameters of the Tested DR-HVDC System 